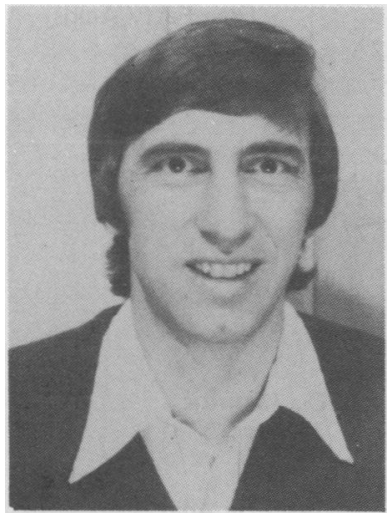

N. Armstrong

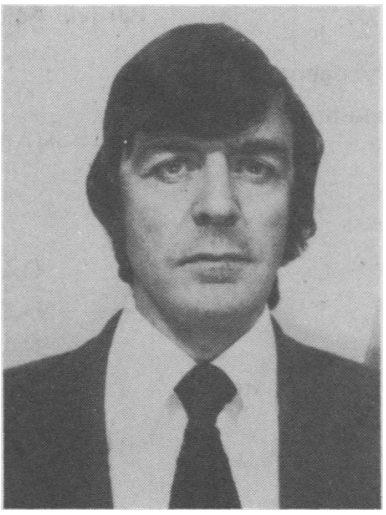

B. Davies

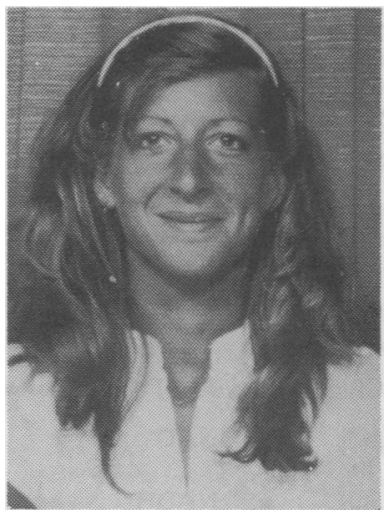

Michelle Heal

\title{
THE SPECIFICITY OF ENERGY UTILISATION BY TRAINED AND UNTRAINED ADOLESCENT BOYS
}

\author{
N. ARMSTRONG, MSc*, B. DAVIES, PhD** and Michelle HEAL, BEd* \\ *Movement Science Laboratory, City of Liverpool College of Higher Education \\ * * Metabolic Profile Unit, University of Salford
}

\begin{abstract}
This study examined the relationship between estimates of alactacid anaerobic power, lactacid anaerobic power and aerobic power in a sample of trained swimmers (age $14.4 \mathrm{yr} ., \mathrm{n}=8$ ) and a sample of untrained boys (age $13.7 \mathrm{yr}$., $n=13$ ). The anaerobic power outputs were estimated using a modification of the Wingate Anaerobic Test and aerobic power was estimated using a continuous, incremental cycle ergometer test. In addition to leg power outputs the swimmers' arm power using each energy system was estimated and compared with the corresponding leg value.

There was no relationship between the estimates of the power of the three energy systems with either the trained or untrained boys. Furthermore with the trained boys there was no relationship between estimates of the power of the same energy system utilised by different limbs.

The data support a specificity hypothesis of energy utilisation during exercise with both trained and untrained adolescent boys.

Key Words: Anaerobic power, Aerobic power, Children, Swimmers.

\section{INTRODUCTION}

The energy requirements of muscular contraction are met by the hydrolysis of the high energy phosphagens, glycolysis and oxidative mechanisms in a sequentially contributing and overlapping fashion. The direct

\section{Correspondence to:}

Neil Armstrong,

Movement Science Laboratory,

City of Liverpool College of Higher Education,

Liverpool Road.

Prescot,

Merseyside,

L34 1NP

splitting of the phosphagens, primarily adenosine triphosphate (ATP) and creatine phosphate (CP), precedes all other exergonic processes in the muscles and can proceed at a much greater rate than their re-synthesis. The concentrations of ATP and CP in skeletal muscle however are limited to approximately $\mathbf{5 . 0}$ and $\mathbf{1 7 . 0}$ mmol. $\mathrm{kg}^{-1}$ wet muscle respectively (Åstrand and Rodahl, 1977, p. 32) and maximal exercise can only be sustained by this alactacid anaerobic system for perhaps 6s (Margaria et al, 1964).

The lactacid anaerobic system is initiated before the phosphagen stores are maximally depleted (McGilvery, 1975; Saltin et al, 1971) and ATP is re-synthesised during the catabolism of glucose/glycogen to lactic acid.
\end{abstract}




\section{LACTACID ENERGY SYSTEM}

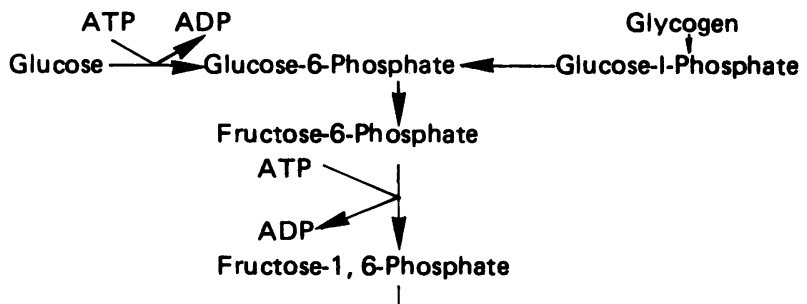

Glyceraldehyde-3-Phosphate Dihydroxyacetone Phosphate

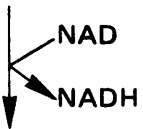

1,3-Diphosphoglycerate

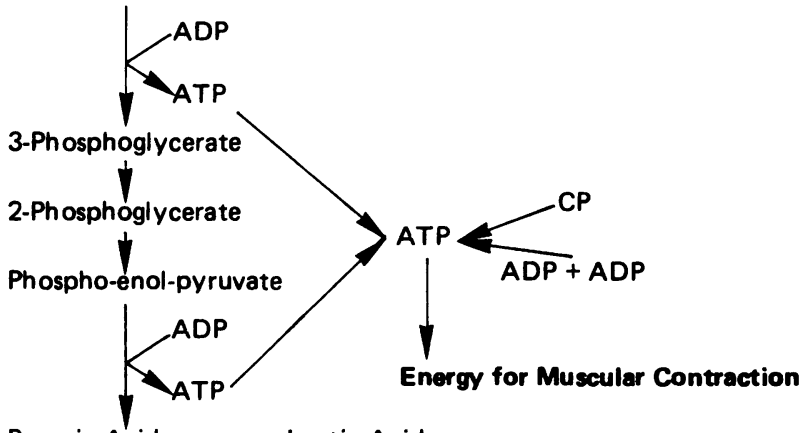

Pyruvic Acid

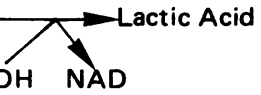

\section{ALACTACID ENERGY SYSTEM}

\section{KEY}

ADP - Adenosine diphosphate

ATP - Adenosine triphosphate

NAD - Nicotinamide-adenine dinucleotide

NADH - Nicotinamide-adenine dinucleotide, reduced form

CP - Creatine phosphate

Acetyl Co-A - Acetyl coenzyme A

$F A D$ - Flavin-adenine dinucleotide

FADH - Flavin-adenine dinucleotide, reduced form

GDP - Guanosine diphosphate

GTP Guanosine triphosphate

Fig. 1: Schematic representation of anaerobic energy systems.

The aerobic system is the most efficient in terms of ATP production and has a much greater capacity for energy generation than the anaerobic systems. The oxygen transport system, however, is slow to adapt to the demands of heavy exercise and the rate at which ATP can be generated through glycolysis/glycogenolysis

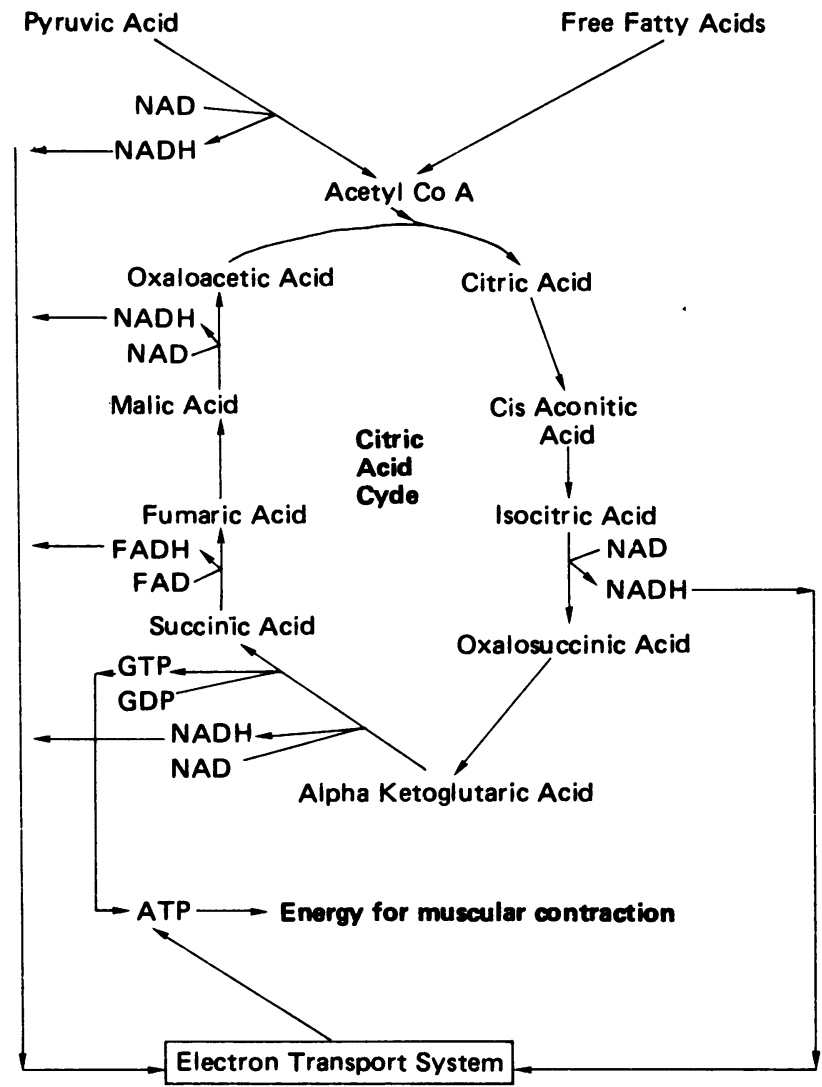

\section{KEY}

ADP - Adenosine diphosphate

ATP - Adenosine triphosphate

NAD - Nicotinamide-adenine dinucleotide

NADH - Nicotinamide-adenine dinucleotide, reduced form

Acetyl Co-A - Acetyl coenzyme A

FAD - Flavin-adenine dinucleotide

FADH - Flavin-adenine dinucleotide, reduced form

GDP - Guanosine diphosphate

GTP Guanosine triphosphate

Fig. 2: Schematic representation of the aerobic energy system.

in muscle greatly exceeds that of the aerobic system. As a result, near the beginning of exercise when mitochondrial oxygen consumption is not optimal and during very intense exercise when pyruvic acid production exceeds the mitochondrial capacity to oxidise it the lactacid anaerobic system is of primary importance.

The predominant energy system for any given 
exercise is a function of the total amount of energy demanded by the exercise and the rate at which it is supplied. Furthermore recent research has identified genetically determined muscle fibre types possessing different contractile and metabolic properties (Barnard et al, 1970; Saltin et al, 1971) and it seems that preferential recruitment of specific fibre types is dependent upon the precise demands of the exercise. Consequently subjects capable of high anaerobic performance may or may not have a similar aerobic potential. The specificity or generality of adolescents' energy systems has not to our knowledge been documented and comparisons between trained and untrained children have not been investigated.

This study was therefore designed to investigate the relationship between estimates of the anaerobic and aerobic power of both trained and untrained adolescent boys and to compare our power output scores with data collected elsewhere.

\section{METHODS}

\section{Subjects}

The subjects were volunteers who were habituated to the laboratory environment. The trained group consisted of eight male swimmers who were actively engaged in seven training sessions per week swimming at least 7,000 $\mathrm{m}$ per session augmented with arm dominated, high intensity dryland exercises. The untrained group consisted of thirteen boys of similar age. The physical characteristics of all subjects are displayed in Table $I$.

\section{TABLE I}

Physical characteristics of subjects

$\begin{array}{lccl} & \begin{array}{c}\text { Age } \\ (\mathrm{yr})\end{array} & \begin{array}{c}\text { Weight } \\ (\mathrm{kg})\end{array} & \begin{array}{c}\text { Height } \\ (\mathrm{m})\end{array} \\ \begin{array}{l}\text { Trained swimmers } \\ \text { (n=8) }\end{array} & \times 14.4 & 61.7 & 1.73 \\ & \mathrm{~s} 0.8 & 6.2 & 0.08 \\ & \text { range } 13.6-15.6 & 56.2-70.1 & 1.60-1.85 \\ \text { Untrained boys } & \mathrm{x} 13.7 & 52.5 & 1.62 \\ \text { (n=13) } & \mathrm{s} 0.3 & 7.5 & 0.09 \\ & \text { range } 13.4-14.3 & 42.3-64.7 & 1.47-1.75\end{array}$

\section{Anaerobic Power Test}

A modification of the Wingate Anaerobic Test (WAnT) was used to estimate both alactacid and lactacid anaerobic power. The WAnT is a recently developed 30s supramaximal pedalling test in which the resistance is adjusted relative to body weight and power output can be computed every 5s (Bar-Or, 1977). The procedure has been shown to be reliable, valid and related to the preponderance of fast twitch muscle fibres (Bar-Or et al, 1977; Inbar et al, 1979; Inbar and Bar-Or, 1977).
Recent pilot studies have established that in our laboratory the optimal resistance for adolescent boys is 69 g. $\mathrm{kg}^{-1}$ and the subject must be allowed to overcome the initial inertia before the resistance is applied (Armstrong and Ellard, 1983).

The subject sat on a Monark cycle ergometer suitably adjusted for his leg length and with the required resistance of $69{\mathrm{~g} . \mathrm{kg}^{-1}}^{-1}$ pre-set and held by an experimenter. The pedals of the ergometer were placed in the horizontal position ready for the subject to commence pedalling with his preferred leg. On the command "go" the subject, without rising from his seat, started to pedal as fast as he could until told to stop. An experimenter supported the resistance for exactly $5 \mathrm{~s}$ at which point a timer and digital counter were activated simultaneously. The digital counter was electrically driven and recorded the number of wheel revolutions. Once the resistance had been applied the number of revolutions was noted every $5 \mathrm{~s}$ throughout the $30 \mathrm{~s}$ testing period. Strong verbal encouragement was given to all subjects. Power output was computed from the formula:

Power $=$ no. of revs. $\times$ resistance $\times$ wheel circumference time

Lactacid anaerobic power was calculated from the total number of revolutions in the final 25s of the test. Alactacid anaerobic power was computed using the peak number of revolutions in any $5 \mathrm{~s}$ period and always occurred in the first 5 s period recorded after the application of the resistance.

The anaerobic power of the swimmers' arms was determined in a similar manner. Our pilot work established that for the present subjects the optimal arm cranking resistance was 44 g. kg-1 and a corresponding procedure to that described for leg pedalling was used to determine alactacid anaerobic power and lactacid anaerobic power of the arms.

\section{Aerobic Power Test}

The peak oxygen uptake (peak $\mathrm{VO}_{2}$ ) was used as the criterion measure of aerobic power and it was determined using cycle ergometry in order to allow direct comparisons between aerobic and-anaerobic power estimates.

Peak $\mathrm{VO}_{2}$ with the legs was determined on a Monark cycle ergometer using a continuous, incremental protocol and a constant pedal rate of $60 \mathrm{rev} \cdot \mathrm{min}^{-1}$. Following a three minute warm-up at an intensity of $88 \mathrm{~W}$ the exercise intensity was increased by increments of $29 \mathrm{~W}$ every three minutes until voluntary exhaustion. Each subject was given strong verbal encouragement to pedal for as long as possible with the intent of pushing him to his true maximum. 
The swimmers' peak $\mathrm{VO}_{2}$ with the arms was determined by arm cranking a Monark cycle ergometer at a rate of $60 \mathrm{rev} \cdot \mathrm{min}^{-1}$. A three minute warm-up at an intensity of $29 \mathrm{~W}$ was followed by continuous, incremental increases of $29 \mathrm{~W}$ every three minutes until voluntary exhaustion. Each subject was given strong verbal encouragement to continue as long as he could.

The subjects' respiratory gases passed via a low resistance valve into an on-line gas analysis system which was calibrated prior to each test against a Lloyd-Haldane chemical gas analyser and a Tissot gasometer. Heart rate was recorded using a bipolar lead.

\section{RESULTS AND DISCUSSION}

The subjects' mean maximal aerobic and anaerobic power outputs are presented in Table II. In absolute terms the mean power output of the trained group was significantly greater than the untrained group with each energy system $(p<.01)$ but when power output was expressed relative to body weight the differences were insignificant $(p>.01)$.

Several subjects did not exhibit an oxygen uptake pleateau at the point of voluntary exhaustion but this is a well documented phenomenon in children (Åstrand, 1952; Cumming and Friesen, 1967) and since each of our subjects was strongly motivated to reach his true maximum the peak $\mathrm{VO}_{2}$ values were accepted as maximal regardless of whether a $\mathrm{VO}_{2}$ pleateau was established. The maximum aerobic power of children using cycle ergometry is well documented (Shephard, 1971,1978 ) and the mean values presented here compare very favourably with those reported elsewhere. Arm cranking $\mathrm{VO}_{2}$ max in children is rarely determined but the data in the present study are similar to those we have previously reported using a biokinetic swimbench (Armstrong and Davies, 1981). The alactacid anaerobic power data fit neatly into the classification outlined by Pirnay and Criellard (1980) who concluded that in boys alactacid anaerobic power, as estimated by cycle ergometry, increases from 7.7 W. $\mathrm{kg}^{-1}$ to 10.1 W. $\mathrm{kg}^{-1}$ from the age of 12 to 19 years. We can find no other study with which to directly compare our arm cranking data although Bar-Or and Inbar (1978) used a similar test with younger boys and elicited absolute values substantially less than those reported here.

Several cycle ergometer tests involving supramaximal efforts, (i.e. power outputs greater than that necessary to elicit $\mathrm{VO}_{2} \max$ ), ranging from 30 s to 120 s duration have been used to evaluate the lactacid anaerobic energy system (Cumming, 1973; Katch and Weltman, 1979). In the light of recent data which have illustrated that maximal exercise induces a more rapid $\mathrm{VO}_{2}$ increase in children than in adults (Armstrong et al, 1982; Macek and Vavra, 1980a, 1980b) a 30s test seems to be more appropriate for use with children if the aerobic
TABLE II

Descriptive measures associated with maximal aerobic and anaerobic exercise.

$\begin{array}{cc}\begin{array}{c}\text { Untrained } \\ \text { boys }\end{array} & \begin{array}{c}\text { Trained } \\ \text { boys }\end{array} \\ (n=13) & (n=8)\end{array}$

Cycling data

peak $\mathrm{VO}_{2}$, I. $\mathrm{min}^{-1}$

2.91

peak $\mathrm{VO}_{2}, \mathrm{ml} \cdot \mathrm{kg}^{-1}, \mathrm{~min}^{-1}$

0.60

55.3

$\pm \quad 7.9$

alactacid anaerobic power, $W$.

437.1

$\pm 102.90$

alactacid anaerobic power, W. .g $^{-1}$

8.5

$\pm \quad 1.29$

lactacid anaerobic power, $\mathbf{W}$.

348.0

$\pm \quad 63.32$

6.6

$\pm \quad 0.80$

3.43

$\pm 0.47$

58.3

$\pm \quad 7.6$

563.7

$\pm 80.39$

9.2

$\pm 0.88$

429.2

$\pm 63.50$

lactacid anaerobic power, W. $\mathrm{kg}^{-1}$

6.9

$\pm 0.51$

Arm cranking data

peak $\mathrm{VO}_{2}, \mathrm{I} \cdot \mathrm{min}^{-1}$

2.48

peak $\mathrm{VO}_{2}, \mathrm{ml} \mathrm{kg}^{-1}, \mathrm{~min}^{-1}$

alactacid anaerobic power, W.

alactacid anaerobic power, W. $\mathrm{kg}^{-1}$

$\pm \quad 0.43$

40.2

$\pm \quad 6.2$

332.4

$\pm \mathbf{3 3 . 3 3}$

5.4

$\pm 0.39$

lactacid anaerobic power, $\mathbf{W}$.

256.1

$\pm 44.11$

4.2

$\pm 0.54$

Values are mean \pm standard deviation

component is to be minimised. As the contribution of the lactacid anaerobic system to the power output during the initial 5s of pedalling against the resistance will be small we have chosen to utilise the power output during the final $25 \mathrm{~s}$ of the test as our criterion of lactacid anaerobic power. There are no other studies with which to compare our data but the leg power output of our boys over the whole 30 s period is in general agreement with data reported elsewhere (Bar-Or and Inbar, 1978; Grodjinovsky et al, 1980; Palgi, 1980). The swimmers' arm power scores over the 30s period are substantially higher than those reported by other investigators using similar methodology with younger subjects (Bar-Or and Inbar, 1978; Inbar and Bar-Or, 1977).

The boys' aerobic power with both arms and legs compares very favourably with adult data (Åstrand, 
1952; Robinson, 1938) but the alactacid and lactacid anaerobic power of the legs are substantially less than adult scores obtained using similar methodology (Bar-Or, 1977; Taunton et al, 1981). This may be a function of the test in which the greater strength of the adult subjects enables them to cope with higher resistances. In contrast the swimmers' arm alactacid and lactacid anaerobic power are comparable to the adult data presented by Ayalon et al (1974) in the only similar study available. This may be due to the high intensity arm training programme followed by the swimmers in the present study but we feel that the very low resistance utilised by Ayalon was probably less than optimal for his subjects.

\section{TABLE III}

\section{Intercorrelation matrix (trained swimmers)}

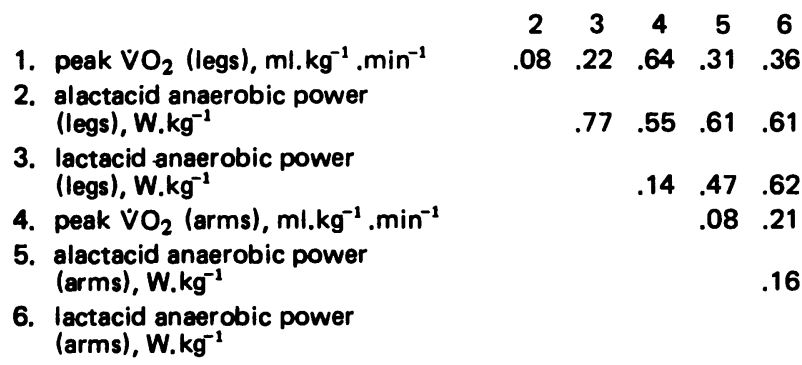

All correlation coefficients are non-significant $(p>.01)$

\section{TABLE IV}

Intercorrelation matrix (untrained boys)

$\begin{array}{lll}\text { 1. peak } \mathrm{VO}_{2} \text { (legs), } \mathrm{ml} \cdot \mathrm{kg}^{-1} \cdot \mathrm{min}^{-1} & 2 & 3 \\ \text { 2. alactacid anaerobic power (legs), } \mathbf{W} \cdot \mathrm{kg}^{-1} & .46 & .47 \\ \text { 3. lactacid anaerobic power (legs), } \mathbf{W} \cdot \mathbf{k g}^{-1} & & .29\end{array}$

All correlation coefficients are non-significant $(p>.01)$

Inter-correlation matrices for the parameters studied are presented in Tables III and IV. None of the correlation coefficients are significant $(p>.01)$ and these findings indicate that the three energy systems are essentially unrelated to each other in both trained and untrained boys. Furthermore with the trained boys the energy systems are specific to the limb muscle mass being utilised. There is no study with which we can directly compare our findings and the data available are not unequivocal. Katch and Weltman's (1979) adult data support a specificity hypothesis of energy utilisation during exercise and this is in agreement with the work of Pirnay and Criellard (1980) but in contrast to the children described by Godfrey (1974). Palgi's (1980) results indicate that in 10 to 14 year old children there is a substantial relationship between measures of aerobic and anaerobic function. The explanation underlying our results may well be found in the boys' muscle fibre profiles. High aerobic power may reflect a greater percentage of high oxidative - slowtwitch fibres in those muscles used and high anaerobic power may reflect a greater percentage of low oxidative - fast twitch fibres in the muscles used. The lack of relationship in the trained boys between arm and leg use of the same energy system is not an unexpected finding as a number of studies have shown that the effects of training are highly specific to the trained muscle (Henriksson, 1977; Pendergast et al, 1979; Saltin et al, 1976) and the swimmers are essentially arm trained athletes.

In conclusion, all of the estimates of arm power and the estimates of leg aerobic power reported here compare very favourably with data reported elsewhere for both children and adults. The estimates of alactacid and lactacid anaerobic power of the legs compare favourably with other children's data but are substantially less than the data available on adults. No relationship between estimates of the power of the three energy systems has been demonstrated with either trained or untrained boys and with the trained boys no relationship between estimates of the power of the same energy system utilised by different limbs has been found. The data therefore support a specificity hypothesis of energy utilisation during exercise by adolescent boys.

\section{ACKNOWLEDGEMENT}

We acknowledge the technical assistance of Rhona Ellard, Carol Ketley, John Mulhall and Jill Pritchard and we are grateful for the co-operation of Bruce Lawrie, Head Coach of the Salford Triple S Club and the Headmaster and PE Staff of Huyton Roby Comprehensive School.

\section{REFERENCES}

Armstrong, N. and Davies, B., 1981 "An ergometric analysis of age group swimmers". Brit.Journ.Sports Med. 15 (1): 20-26.

Armstrong, N., Davies, B. and Mulhall, J., 1982 "Transient oxygen uptake in trained children at the onset of maximal arm and leg exercise". Brit.Journ.Sports Med. i6 (2): 111. 
Armstrong, N. and Ellard, R., 1983 "Alactacid anaerobic power in trained and untrained adolescent boys". In: R. Bartlett, L. E. Cooke, D. W. Kellett and S. Wolfson (eds.), Proceedings of the "Sport and Science Conference, Crystal Palace, 1982", p. 344-346, Society of Sports Sciences, Manchester Polytechnic.

Åstrand, P. O., 1952. Experimental Studies of Physical Working Capacity in Relation to Sex and Age. Munksgaard, Copenhagen.

Åstrand, P. O. and Rodahl, K., 1977. Textbook of Work Physiology (2nd edition). McGraw-Hill, New York.

Ayalon, A., Inbar, O. and Bar-Or, O., 1974 "Relationships among measurements of explosive strength and anaerobic power". In: R. C. Nelson and C. A. Morehouse (eds.), Biomechanics IV, p. 572-578, University Press, Baltimore.

Bar-Or, O., 1977 "Wingate anaerobic test". Wingate Institute Report. In: J. E. Taunton, H. Maron and J. G. Wilkinson, 1981, "Anaerobic performance in middle and long distance runners". Can.J.App.Sp.Sc. 6: 109-113.

Bar-Or, O., Dotan, R. and Inbar, O., 1977 "A 30 sec. all out ergometric test - its reliability and validity for anaerobic capacity". Israel J.Med.Sci. 13: 126.

Bar-Or, O. and Inbar, O., 1978 "Relationships among anaerobic capacity, sprint and middle distance running of school children". In: R. J. Shephard and H. Lavallee (eds.), Physical Fitness Assessment - Principles, Practice and Application, p. 142-147, Thomas, Springfield.

Barnard, R. J., Edgerton, V. R. and Peter, J. B., 1970 "Effect of exercise on skeletal muscle. I. Biomechanical and histochemical properties"'. J.Appl.Physiol. 28: 762-766.

Cumming, G. R. 1973 "Correlation of athletic performance and aerobic power in 12 to 17 year old children with bone age, calf muscle, total body potassium, heart volume and two indices of anaerobic power". In: O. Bar-Or (ed.), Proceedings of the Fourth International Symposium on Pediatric Work Physiology, p. 109-134, Wingate Institute, Israel.

Cumming, G. R. and Friesen, W. 1967 "Bicycle ergometer measurements of maximal oxygen uptake in children". Can.J.Physiol. 45: 937-946.

Godfrey, S., 1974. Exercise Testing in Children. Saunders, London.

Grodjinovsky, A., Inbar, O., Dotan, R. and Bar-Or, O., 1980 "Training effect on the anaerobic performance of children as measured by the Wingate anaerobic test". In: K. Berg and B. O. Eriksson (eds.), Children and Exercise IX, p. 139-148, University Park Press, Baltimore.

Henriksson, J., 1977 "Training induced adaptation of skeletal muscle and metabolism during sub-maximal exercise". J.Physiol. 270: 661-675.

Inbar, O. and Bar-Or, O., 1977 "Relationship of anaerobic and aerobic arm and leg capacities to swimming performance of 8 to 12 year old children". In: R. J. Shephard and H. Lavallee (eds.), Frontiers of Activity and Child Health, p. 283292, Pelican, Quebec.

Inbar, O., Kaiser, P., Dotan, R., Bar-Or, O., Schéle, R. and Karlsson, J., 1979 "Indices of the Wingate anaerobic test, fibre-type distribution and running performance in man". Med.Sci.Sp. 11: 89.

Katch, V. L. and Weltman, A., 1979 "Inter-relationship between anaerobic power output, anaerobic capacity and aerobic power". Ergonomics 22: 325-332.

Macek, M. and Vavra, J., 1980a "Oxygen uptake and heart rate with transition from rest to maximal exercise in prepubertal boys". In: K. Berg and B. O. Eriksson (eds.), Children and Exercise IX, p. 64-68, University Park Press, Baltimore.

Macek, M. and Vavra, J., 1980b "The adjustment of oxygen uptake at the onset of exercise: a comparison between prepubertal boys and young adults". Int.J.Sp.Med. 1: 70-72. 
Margaria, R., Cerretelli, R. P. and Mangili, F., 1964 "Balance and kinetics of anaerobic energy release during strenuous exercise in man". J.Appl.Physiol. 19: 623-628.

McGilvery, R. W., 1975 "The use of fuels for muscular work". In: H. Howald and J. R. Poortmans (eds.), Metabolic Adaptations to Prolonged Physical Exercise, p. 12-30, Birkhauser Verlag, Basel.

Palgi, Y., 1980 "Physiological and anthropometric factors underlying endurance performance in boys and girls". Unpublished Ed. D. Thesis, Columbia University Teachers College, New York.

Pendergast, D. R., Ceretelli, P. and Rennie, D. W., 1979 "Aerobic and glycolytic metabolism in arm exercise". J.Appl. Physiol. 47: 754-760.

Pirnay, F. and Criellard, J. M., 1980 "Anaerobic power in children and adolescents". Proceedings of the Second European Seminar on Testing Physical Fitness, p. 39-44, University of Birmingham.

Robinson, S., 1938 "Experimental studies of physical fitness in relation to age". Arbeitsphysiol. 10: 251-323.

Saltin, B., Gollnick, P. D., Piehl, K. and Eriksson, B., 1971 "Metabolic and circulatory adjustments at onset of exercise". In: A. Gilbert and P. Guille (eds.), Onset of Exercise, p. 63-76, University of Toulouse Press, Toulouse.

Saltin, B., Nazar, K., Costill, D. L., Stein, E., Jansson, E., Essen, B. and Gollnick, P. D., 1976 “The nature of the training response: peripheral and central adaptations to one-legged exercise". Acta Physiol.Scand. 96: 289-305.

Shephard, R. J., 1971 "The working capacity of school children". In: R. J. Shephard (ed.), Frontiers of Fitness, p. 319 345, Thomas, Springfield.

Shephard, R. J., 1978 "The growth of working capacity". In: R. J. Shephard, Human Physiological Work Capacity, p. 179-232, Cambridge University Press, Cambridge.

Taunton, J. E., Maron, H. and Wilkinson, J. G., 1981 "Anaerobic performance in middle and long distance runners". Can.J.Appl.Sp.Sc. 6: 109-113.

CORRESPONDENCE

19 Lucknow Avenue, Mapperley Park, Nottingham

To the Editor:

Dear Sir,

\section{ACROMIO-CLAVICULAR DISLOCATION}

I thought you may be interested to learn of the "value" of an acromioclavicular dislocation. Recently I saw a 22 year old Rugby player in my clinic who had been troubled for some time with anterior knee pain. An incidental finding on general examination uncovered a dislocated right acromioclavicular joint. He told me that this injury had occurred three years previously and he had been told that no surgical treatment was necessary.

I do not intend to debate the need or possible techniques of surgical correction of acromioclavicular dislocation, but suffice it to say that this prop forward had not only a full range of pain-free movement of the affected shoulder, but used the injury to great advantage. He demonstrated the usefulness of this injury with me in the clinical area. He used the bony strut of the right shoulder to great effect to stab my cheek, and eye, and caused considerable discomfort by abrading my face. When he stood up from the scrum position his comment was "It's great isn't it, you can really aggravate the opposition with it. It is a shame I did not dislocate the other side as well".

Could this case be regarded as "one in the eye" for those orthopods who advocate reduction and pinning of acromioclavicular dislocations?

Yours sincerely,

ANGUS HUGHES,

Locum Senior Orthopaedic Registrar 